\title{
Una aproximación al concepto de literatura en Mario Vargas Llosa
}

\section{Mario Vargas Llosa's concept of Literature: an approximation}

\author{
Henry César Rivas Sucari ${ }^{1 a}$, José Luis Rodríguez Eguizabal ${ }^{2}$, Ana María Flores Núñez $^{3}$, \\ Aldo Rafael Medina Gamero ${ }^{4}$, Fidel Almirón Quispesivana ${ }^{5}$ \\ Universidad Peruana de Ciencias Aplicadas- UPC, Lima, Perú ${ }^{1}$ \\ Universidad Nacional Mayor de San Marcos-UNMSM, Lima, Perú ${ }^{2}$ \\ Filiación: Universidad San Ignacio de Loyola- USIL, Lima, Perú ${ }^{3}$ \\ Universidad Tecnológica del Perú, Lima, Perú ${ }^{4}$ \\ Universidad Nacional de San Agustín de Arequipa- UNSA, Arequipa, Perú ${ }^{5}$
}

iD ORCID ID: https://orcid.org/0000-0001-9703-8336 1

(iD) ORCID ID: https://orcid.org/0000-0003-0978-7164²

(iD) ORCID ID: https://orcid.org/0000-0002-6419-1577³

(iD ORCID ID: https://orcid.org/0000-0003-3352-87794

(iD) ORCID ID: https://orcid.org/0000-0001-8050-4177

Recibido: 8 de setiembre de 2021

Aceptado: 30 de diciembre de 2021

\section{Resumen}

El presente artículo tiene como objetivo definir el concepto de literatura del escritor Mario Vargas Llosa. Para ello, se han revisado algunos de los ensayos donde el escritor plantea definiciones, inferencias, deducciones y aproximaciones con respecto a este concepto. Para este trabajo, se utiliza una perspectiva sobre la definición del concepto de literatura del escritor como creador antes que teórico. Queda prefijado el sentido que se le otorga a este concepto dentro de la línea estética. Algunos de los estudios analizados para esta tarea lo constituyen el discurso La literatura es fuego, Historia secreta de una novela, Cartas a un joven novelista, la tesis Gabriel García Márquez: historia de un deicidio, y La orgía perpetua (Flaubert y Madame Bovary). A partir de estos textos, se propone una definición aproximativa sobre el concepto de literatura a partir del pensamiento de Mario Vargas Llosa.

Palabras clave: Mario Vargas Llosa, literatura, ficción, referencialidad, teoría de la novela, Gabriel García Márquez.

\footnotetext{
Abstract

The present article aims to establish the concept of literature in the thinking of the writer Mario Vargas Llosa. To this end, some of the essays where the writer raises definitions, inferences, deductions and approximations regarding this concept have been reviewed. This study works from

${ }^{\text {a}}$ Correspondencia al autor:

E-mail: Correo: pchuhriv@upc.edu.pe

Financiamiento: Dirección de Investigación de la Universidad Peruana de Ciencias Aplicadas [A-151-2021-2]
} 
a perspective on the definition of the concept of literature of the writer as creator rather than theoretical. The sense that is given to this concept within the aesthetic line is fixed. Some of the studies analyzed for this task are constituted by the followings works: La literatura es fuego; Historia secreta de una novela, Cartas a un joven novelista; the thesis Gabriel García Márquez: historia de un deicidio and La orgía perpetua (Flaubert y Madame Bovary). From these texts we will propose an approximate definition of the concept of literature based on the thought of Mario Vargas Llosa.

Keywords: Mario Vargas Llosa, literature, fiction, referentiality, theory of the novel, Gabriel Garcia Marquez.

\section{Introducción}

El concepto de literatura que se conoce en la actualidad es plurisemántico; es decir, puede poseer varios significados parecidos y contrarios. Desde la Poética de Aristóteles, las interpretaciones han estado orientadas hacia la mímesis, la ficción y lo verosímil. En la actualidad, muchos teóricos han establecido serias interpretaciones y propuestas, las cuales giran en torno no solo del objeto literario (obra), sino en el de su producción y contexto (autores, estudios, mercado, crítica, etc.). Para Todorov (1991), existen dos líneas para una conceptualización: la estructural y la funcional. La primera se orienta hacia la imitación y utilización del lenguaje. La segunda, hacia una integración de los elementos contextuales que ofrece la sociedad. En la línea estructural, se sitúan R. Wellek y A. Warren (1969), quienes enfocan su atención hacia los géneros tradicionales como la lírica, la épica y el drama. En cuanto una definición funcional, Terry Eagleton (1988) afirma:

Desde mi punto de vista resulta más útil considerar la "literatura" como un nombre que la gente da de vez en vez y por diferentes razones a ciertos escritos ubicados dentro del campo de lo que Michel Foucault denominó "prácticas discursivas". Si algo va a ser objeto de estudio, es mejor que lo sea todo el campo de las prácticas en vez de únicamente esas que a veces reciben el nombre oscuro de "literatura". (p. 125).

En el caso de la definición de la literatura por parte de otros escritores, para Virginia Woolf (Woolf, 1929, p.47), "Literature is strewn with the wreckage of men who have minded beyond reason the opinions of others." Esta conceptualización está dirigida hacia el efecto social del discurso literario. La literatura debe ser sincera, no debe ser escrita bajo los estándares de los "otros". Existe un concepto de la literatura que parte desde la honestidad de lo narrado por parte del escritor. 
Para Ezra Pound (1934), la literatura debía condensar la realidad: “Great literature is simply language charged with meaning to the utmost possible degree" (p. 36). Se asume que la literatura debe comprender a mayor parte posible de la realidad. Debe contener de forma creativa una presentación de la misma en la mayor cantidad posible. Su poder es la condensación de gran parte de la realidad en las páginas de un libro. Por otro lado, Umberco Eco (2000), más que preguntarse por el concepto de literatura, se pregunta ¿Para qué sirve este bien inmaterial, la literatura?

La literatura permite ejercitar la lengua. Sobre todo, ejercita la lengua como patrimonio colectivo. La lengua, por definición, va donde quiere, ningún decreto celestial, ni político, ni académico, puede detener su camino y hacerla desviarse hacia situaciones que pretenden ser óptimas. La lengua va donde quiere pero es sensible a las sugerencias de la literatura. Sin Dante no habría existido la lengua italiana unificada. (párr.4-5)

Su concepción de literatura se relaciona con el efecto que en la sociedad produce. En este caso, resalta el papel que juega en la lengua de una nación, como en el caso italiano. Para hacer un paralelo, en el caso hispanoamericano la novela El Quijote sería tan importante para la lengua española como la obra La divina comedia para Italia.

Estos conceptos desde perspectivas de escritores se asemejan a los concebidos por Vargas Llosa, sobre todo las dos primeras, pues dirigen su interés a un campo ético y social de la literatura. El cambio Eco, añadiría a la literatura una importancia dentro de la cultura de su propio país. En ese sentido, la literatura es considerada no solo como un arte (novelas, cuentos, poesía, teatro), sino como parte del discurso popular.

Cabe mencionar que no es la finalidad de este ensayo un balance general de todos los conceptos de literatura por parte de teóricos o escritores, pero sí entender la propuesta de Mario Vargas Llosa desde su figura como escritor antes que teórico de la literatura. Para el Nobel, la definición de literatura se relaciona con la noción tradicional, la estructural. Su concepto es abordado desde las obras literarias. En este artículo, intentamos una aproximación al concepto de literatura y los elementos que la constituyen a partir de las conferencias, estudios, libros y artículos que el autor de La casa verde ha producido sobre este tema.

La metodología que hemos utilizado para la elaboración de este ensayo es cualitativa, la cual consiste en el recojo de información pertinente para su posterior interpretación. Los textos seleccionados configuran los discursos, estudios y tesis que Vargas Llosa ha escrito en torno a su 
poética. Hemos identificado al discurso La literatura es fuego (1985) como un documento importante donde se percibe algunas definiciones en torno al concepto de literatura. Historia secreta de una novela (1971a) constituye una memoria formidable sobre la creación literaria, en este caso de una novela emblemática como es La casa verde. En Cartas a un joven novelista (1997) se destaca la formulación sobre la carrera del escritor y las estrategias para la performance literaria. La tesis Gabriel García Márquez: historia de un deicidio, y La orgía perpetua (Flaubert y Madame Bovary) son dos formas que el escritor utiliza para extrapolar sus teorías de la ficción basadas en obras de otros autores, a los cuales él admira. Los ensayos sobre su relación con Sartre debaten la relación entre lo estético y lo político para la concepción de la literatura. En ese sentido, el objetivo de este ensayo es establecer el concepto de literatura de Mario Vargas Llosa.

\section{"La literatura es fuego", y el concepto ideológico de la literatura}

El discurso pronunciado por Mario Vargas Llosa en la ceremonia para recibir el premio Rómulo Gallegos en 1967 (1985) posee, claramente, un carácter ideológico. De acuerdo con el contexto en el que fue escrito, sigue la línea sobre el concepto de literatura ligado al de la función del "intelectual comprometido". Esta etapa del escritor está marcada por la influencia de la filosofía de Jean Paul Sartre. El filósofo francés escribió ¿Qué es la literatura? (1967). En ese estudio, se define la literatura como una actividad comprometida con la sociedad y con las personas más vulnerables. En ese sentido, existe, entonces, un compromiso ético, social y político del escritor y su obra. Este posee una responsabilidad social con el mundo que le ha tocado vivir: Esa idea del escritor comprometido será la misma que Vargas Llosa utilizará para su discurso, pues él considera que la literatura significa inconformismo y rebelión.

Por otro lado, se entiende una idea de literatura vinculada al aspecto social, pero sin una valoración en esa magnitud por el ámbito estético, al menos no de manera directa, pero sí indirecta, por ejemplo, cuando se cita a Carlos Oquendo de Amat, un poeta cuya única obra Cinco metros de poemas (1927) no concibe una disposición ideológica sino lúdica y posmoderna. Allí encontramos una clave primaria para entender la concepción global de la literatura. No se comprende de otra manera el que siendo La literatura es fuego un discurso de compromiso político resucite la figura de un poeta como Oquendo de Amat.

Más adelante, Vargas Llosa se decanta de Sartre y el concepto utilitarista de la literatura, pues este reduce su significado, lo consigna como herramienta social sin tomar en cuenta, en toda 
su dimensión, el plano artístico y ético. En Los otros contra Sartre (1981b), el escritor arequipeño critica algunos postulados del filósofo francés, "ante la afirmación de Sartre de que el escritor de un país subdesarrollado debería "renunciar momentáneamente a la literatura" o que "frente a un niño que se muere [de hambre], La Náusea es algo sin valor” (1981, p. 25).

La decepción de Vargas Llosa reside en que el propio Sartre contradice el valor que antes había adjudicado a la literatura. Más adelante, apela a la técnica literaria de los textos estéticosliterarios, como la novela, para criticar a su antes admirado filósofo. En "Flaubert, Sartre y la nueva novela" (1981a), critica la postura ideológica sartreana para tomar partido por el método de trabajo y las técnicas narrativas de Gustave Flaubert. En ese sentido, se colige otra dimensión para explicar o entender lo que es la literatura para Vargas Llosa: no solo el aspecto social y utilitarista de la revolución, sino otro que gira en torno a su dimensión estética ${ }^{\mathrm{b}}$.

Luego, en "Sartre, veinte años después" (1981c), Vargas Llosa rechaza la teoría del compromiso esgrimida por Sartre. Cita la posición del filósofo sobre los poetas, pues este señala que no pueden comprometerse, pues para ellos las palabras constituyen cosas y no signos; es decir, han perdido su dimensión comunicativa. Otra objeción es que Sartre olvida el rol de los componentes irracionales en el proceso de creación literaria: racionalidad versus emotividad.

Si bien, en un inicio, un joven Vargas Llosa condecía un concepto de literatura sartreano vinculado hacia la insurrección, la rebeldía, el utilitarismo e inconformismo, como en su discurso La literatura es fuego, después se aleja de esta concepción para vincular la literatura hacia su dimensión artística ${ }^{c}$. Esta consiste en una de carácter liberal, y bajo los modelos estéticos de los grandes innovadores de la novela, como Flaubert y Faulkner.

Mario Vargas Llosa evoluciona su concepción (y valoración) de literatura para circunscribirla no solo al aspecto ideológico, sino, también, estético. En realidad, no podemos afirmar que ignoraba la dimensión artística, pero sí entendemos la valoración ideológica que proponía para la literatura. En el sentido del discurso La literatura es fuego, se la percibe desde la influencia ideológica de Jean Paul Sartre. Y como hemos descrito, más adelante agregaría una importancia mayor a la dimensión artística y técnica.

${ }^{\text {b }}$ Al respecto, el estudio de Camilo Fernández (2014) destaca la influencia cultural francesa en la ensayística de Mario Vargas Llosa

${ }^{\mathrm{c}}$ Al respecto Morales Mena (2018) enfatiza que al analizar los ensayos de Vargas Llosa no se toma en cuenta los recursos narrativos y retóricos propios del género. 


\section{Historia secreta de una novela y la concepción estética de la literatura}

Historia secreta de una novela (1971a) es un breve ensayo de Mario Vargas Llosa que tiene como objetivo reconstruir el proceso de la escritura de su novela La casa verde (1966). Si bien, el escritor afirma que este ensayo no propone una versión técnica de la escritura de una novela, lo hace de manera concreta. La posición que asume para la novela y para la literatura es la elaboración de la ficción. En este caso, a diferencia de la conferencia La literatura es fuego, donde centraba la importancia y la definición de esta dentro del plano ideológico, aquí sus reflexiones son plenamente estéticas. No se propone de manera directa una apelación a los juicios técnicos de la novela, pero sí compone una teoría de la novela propia tomando como base la fícción y los denominados "demonios".

Casi todas las novelas de Vargas Llosa son producto de su experiencia vital. Sigue una tradición realista europea y latinoamericana que predominó en el siglo XX, el escribir tomando como base experiencias personales o situaciones contextuales que, por alguna razón, constituyen una fuente para elaborar sus ficciones. Vargas Llosa no se vio seducido por los innumerables géneros de fantasía y ciencia ficción predominantes en Europa y los Estados Unidos. Su forma de ver la literatura, casi en general, se vincula a una función social de denuncia y rebeldía. No obstante, la dimensión estética también compone su concepción de literatura y la forma cómo concibe sus novelas. En ese sentido, en $\mathrm{HSN}^{\mathrm{d}}$, plantea la dimensión estética y técnica (aunque no sea su propósito) de la literatura. Vargas Llosa recurre a su experiencia vital como la estructurante de sus ficciones. Para describir este proceso cita a los denominados "demonios", que no serían sino obsesiones personales:

Lo que el novelista exhibe de sí mismo no son sus encantos secretos, como la desenvuelta muchacha, sino demonios que lo atormentan y obsesionan, la parte más fea de sí mismo: sus nostalgias, sus culpas, sus rencores. (p.6)

La utilidad de estos "demonios" ayudan a configurar la novela. En HSN, el Nobel explica cómo sus cortas experiencias en la ciudad de Piura fueron tan importantes en su vida. Las razones la constituyen la amistad, las relaciones sociales y el descubrimiento de la sexualidad (la denominada Casa verde). Esos dos momentos en los que reside en Piura, en su niñez y el último año de colegio, le sirven para comprender la dimensión mítica de la niñez (una Casa verde

\footnotetext{
${ }^{\mathrm{d}}$ De esta forma abreviaremos Historia secreta de una novela.
} 
idealizada) y luego en su juventud, la de otra realidad (la "casa verde real", un prostíbulo pobre). Esas experiencias, sumadas a los personajes "reales", son útiles como materia prima para la elaboración de personajes de La casa verde.

En HSN, Vargas Llosa revela, con minuciosidad, cómo elabora los personajes para construir su ficción. Entendemos de dónde proceden, qué relación referencial poseen los reales con los ficticios, cómo las historias personales se superponen con los libros leídos y llegan, luego a poblar La casa verde. Llegamos a comprender todo el acto técnico de la novela, en cuanto al proceso autorreferencial del escritor. La literatura no solo es fuego, sino una elaborada ficción cuya elaboración es planteada de una manera artesanal y efectiva. De este modo, la construcción de este mundo ficcional autónomo llega a cobrar verosimilitud.

Las experiencias personales (vividas, soñadas, oídas, leídas) que fueron el estímulo primero para escribir la historia quedan tan maliciosamente disfrazadas durante el proceso de la creación que, cuando la novela está terminada, nadie, a menudo ni el propio novelista, puede escuchar con facilidad ese corazón autobiográfico que fatalmente late en toda ficción. (p.6)

Se entiende, entonces, que luego de una ardua elaboración de varios años, el producto literario ficcional: la novela, posee una autonomía que difícilmente, para el lector, puede determinarse como "realidad real". O al menos es lo que se pretende el autor. Sin embargo, al registrar las primeras novelas de Vargas Llosa, y en especial La casa verde, la relación paratextual con la figura del escritor, esa línea no está del todo separada para el lector. Recordemos que una característica del realismo es que la verosimilitud de la ficción recreada encuentre en los elementos representados esa mayor coherencia. E incluso a uno de los creadores que prefiguran la teoría de novela de Vargas Llosa, a Gustavo Flaubert, se le llevó a juicio por el argumento de la novela representado de manera casi "real" en Madame Bovary. La pretensión del autor de lograr un mundo ficcional autónomo puede jugarle en contra si el discurso representado logra una verosimilitud poderosa. La historia de la literatura está poblada de muchos de estos casos.

Al existir la Casa verde en la historia piurana, y muchos de los personajes que son recreados en la novela, para el lector común, ese pacto literario se confunde con el real. Esta es una de las consecuencias que le juegan en contra a menudo a los escritores como consecuencia de la 
autorreferencialidad como herramienta primaria para elaborar sus ficciones: "Ya lo sospechaba, pero entonces lo supe de manera flagrante y carnal: la «verdad real» es una cosa y la «verdad literaria» otra y no hay nada tan difícil como querer que ambas coincidan” (1971a, p. 28).

Aunque se citan a varios escritores y novelas, en HSN se reconocen a dos modelos de escritor: a Flaubert y a Faulkner. El primero aporta para Vargas Llosa la increíble dedicación técnica para la elaboración de la ficción y el segundo las técnicas narrativas. Ambos constituyen una manera de entender la literatura, una dedicación exclusiva y profesional, una forma de vivir. Se infiere que la literatura no es solo ideológica para Vargas Llosa, sino también estética. Y para su elaboración comprende un abanico de técnicas y modelos para construir ficciones a partir de la experiencia vital. Añadimos la importancia de la autorreferencialidad en la construcción de la ficción en la narrativa del escritor.

\section{Cartas a un joven novelista y las estrategias literarias en la dimensión ficcional de la literatura}

Cartas a un joven novelista (1997) es un libro que maneja el género epistolar para proponer una teoría de la novela del propio escritor. En ese sentido, Vargas Llosa plantea una serie de reflexiones sobre la vocación del escritor y la forma cómo elabora sus ficciones. A lo largo de sus XII capítulos, podemos percibir cómo se elabora buena parte de su teoría de la novela y la forma cómo concibe el rasgo ficcional de la novela y, por ende, de la literatura. En los primeros dos capítulos, "La parábola de la solitaria" y "El catoblepas", se enfatiza, principalmente, en la vocación del escritor, aunque en el segundo se incide en el carácter de la experiencia vital para construir ficciones:

En cuanto a los temas, creo, pues, que el novelista se alimenta de sí mismo, como el catoblepas, ese mítico animal que se le aparece a San Antonio en la novela de Flaubert (...). En un sentido menos material, desde luego, el novelista está también escarbando en su propia experiencia, en pos de asideros para inventar historias. Y no sólo para recrear personajes, episodios o paisajes a partir del material que le suministran ciertos recuerdos. También, porque encuentra en aquellos habitantes de su memoria el combustible para la voluntad que se requiere a fin de coronar con éxito ese proceso, largo y difícil, que es la forja de una novela. (p.15) 
Vargas Llosa continúa con la idea de que las ficciones son recreaciones de la experiencia vital. Allí reside parte de su propuesta novela. Y va más allá para describir este proceso. Por ejemplo, cita a lo que denomina sus "demonios interiores", que no son otra cosa que motivaciones o pulsiones inconscientes que son asumidas después como elementos estructurantes de sus ficciones: "Me atrevo a ir algo más lejos respecto a los temas de la ficción. El novelista no elige sus temas; es elegido por ellos. Escribe sobre ciertos asuntos porque le ocurrieron ciertas cosas (p.15)"'.

Nos preguntamos ¿cuáles son esos asuntos que le han ocurrido al escritor?, pues son los hechos que han resultado claves en su experiencia vital. Recordemos que las primeras novelas de VLl parten de eventos reconocibles con facilidad en los paratextos de la novela. En La ciudad y los perros (1963) nos comparte la experiencia escolar y militar de un adolescente en el Perú de mediados del siglo XX. La casa verde posee como núcleo clave de su argumento el prostíbulo mítico en el norte del Perú dentro de su historia de niñez y adolescencia. Conversación en la Catedral (1969) narra una época traumática para toda la sociedad peruana, la dictadura de Manuel Odría. En todas estas novelas, la experiencia vital del escritor constituye como fuente para elaborar su ficción.

Inferimos que la literatura es para Vargas Llosa no solo una herramienta ideológica para transformar una sociedad, sino, también, una elevada representación artística, cuya elaboración artesanal es construida a partir de un gran trabajo intelectual: La literatura, también, es un arte. Y la forma de elaborarla, por ejemplo, en el género de la novela, es la construcción de una ficción verosímil. El autor plantea dos niveles de realidad ficcional: la realista y la fantástica. Agrega, además, para su fundamentación, muchos ejemplos de novelas y sus creadores. Describe la forma como estos logran construir ese mundo independiente que es la ficción a partir de representaciones reales, pero jerarquizadas de una manera especial para construir un universo único. En ese sentido, la oposición de planos, lo real y lo irreal, lo realista y lo fantástico constituyen una oposición esencial entre universos de naturaleza diferente. No obstante, las ficciones, también, poseen planos diferenciados, y estos son edificados por los lectores porque poseen una experiencia objetiva sobre el mundo que le rodea. Los escritores realistas se valen de estas opciones para hacer valer la perspectiva del mundo creado (p.59).

Esta forma de explicar las dimensiones de realidad ficcional constituye la manera como Vargas Llosa plantea su teoría de la novela y la manera en la que entiende la literatura. Observamos 
la forma en la que construye una teoría técnica sobre los niveles de realidad escrita en varias novelas de escritores universales. A esto se suma el trabajo del estilo con el lenguaje elaborado para cada historia ficcional, la posición del narrador y el espacio, la forma de configurar el tiempo, las mudas, el salto cualitativo, la caja china, los vasos comunicantes, entre otros elementos técnicos para describir su performance literaria. No podemos, entonces, negar la dimensión estética que el escritor plantea para su concepto de literatura. Como se afirmó antes, el aspecto ideológico, si bien no queda eliminado del todo, sí aparece disminuido en este texto, a comparación de la increíble elaboración técnica para construir ficciones en su narrativa. Es importante, para comprender el mecanismo de la ficción, su hipótesis sobre el tiempo:

La historia se mueve en el tiempo de la ficción como por un territorio, va y viene por él, avanza a grandes zancadas o a pasitos menudos, dejando en blanco (aboliéndolos) grandes períodos cronológicos y retrocediendo luego a recuperar ese tiempo perdido, saltando del pasado al futuro y de éste al pasado con una libertad que nos está vedada a los seres de carne y hueso en la vida real. Ese tiempo de la ficción es pues una creación, al igual que el narrador (50).

Este planteamiento sitúa al tiempo de la ficción de manera independiente al tiempo de la realidad real, como podríamos denominarla. Esta estrategia narrativa sirve para que la ficción literaria logre ese grado de verosimilitud que espera conseguir el escritor. Tanto el tiempo como el narrador y el espacio constituyen elementos claves para poder crear un nivel de realidad ficcional en la novela. Vargas Llosa cita algunos ejemplos extraordinarios en los que su teoría de la novela funciona, como La metamorfosis de Franz Kafka (2012 ), El reino de este mundo de Alejo Carpentier (1949), Tristram Shandy de Laurence Sterne, (2005) Otra vuelta de tuerca de Henry James (2001 ), entre otras. Y aunque cita varios ejemplos donde el tiempo de la novela se puede constituir también en varios tiempos, sin duda uno de los casos más extraordinarios implica en cómo este universo temporal intensificado en la narración funciona en una cronología extraordinaria, por ejemplo, la del Ulises de Joyce (1999). En 24 horas entendemos la vida de Leopoldo Bloom.

En Cartas a un joven novelista, Vargas Llosa ha resumido casi todos los elementos que describe en otros textos sobre su teoría de la novela y, por ende, su concepto de la literatura. Entendemos que supera el plano ideológico para enriquecer el estético. La literatura es un arte y 
su elaboración constituye una artesanía muy compleja y extraordinaria. El elemento fundamental para entender a la literatura es la ficción, pero dentro de una trama técnica. En este libro, se explica cómo un escritor puede conseguir diseñar el mundo ficcional literario para una novela. Se describe, además, la vocación del escritor y los elementos técnicos que debe tomar en cuenta para la escritura literaria.

Aunque no cita a ningún teórico de la literatura, muchos de sus tecnicismos pueden coincidir con la estética de la recepción, por ejemplo, cuando analiza la función del narrador y lector; a la narratología, cuando sin describir ni mencionar el concepto de focalización, nos describe el dato escondido, los vasos comunicantes, el tiempo, el narrador, los niveles de realidad, entre otros elementos fundamentales para la escritura literaria. Como este texto está dirigido a personas que quieran emprender un proyecto literario, las referencias constituyen un grueso de obras importantes de la literatura universal y los modos en que estas fueron escritas.

\section{Gabriel García Márquez: historia de un deicidio, una propuesta de teoría de la novela}

Gabriel García Márquez: historia de un deicidio (1971b) es la tesis con la que Mario Vargas Llosa se graduó como doctor en Filología Románica en la Facultad de Filosofía y Letras de la Universidad Complutense de Madrid. También, forma parte de los cursos que dictó en la Universidad de Puerto Rico y en el King 'College de Londres. En este trabajo se combina el estudio biográfico y contextual del escritor colombiano para relacionarlo con su obra. Este proceso de desentrañamiento biográfico se perfila en el sentido de Historia secreta de una novela. En ambos se intenta describir el proceso en la elaboración de una novela, tomándose las experiencias personales y significativas para explicar la manera compleja en la que se suman a otros elementos para construir las ficciones.

El libro se divide en dos partes. La primera la compone la denominada La realidad real, e incluye dos capítulos; la segunda contrapone al primer título y se denomina La realidad ficticia. Incluye ocho capítulos. Esta forma de aproximarse al estudio de la obra de García Márquez constituye un hito para la historia de la literatura latinoamericana, pues los dos conforman el denominado Boom latinoamericano, además de ser amigos cercanos. Por otro lado, la forma de contraponer la "realidad real" con la "realidad ficticia" e identificar los mecanismos de la creación 
literaria no constituyeron un modelo para el estructuralismo imperante en ese contexto, dentro de los estudios literarios.

En el estudio, interesa la forma cómo un escritor, desde su óptica como creador, aborda la obra de otro escritor. Nos importa, también, cómo, a través de esta investigación, podemos entender la forma en la que Vargas Llosa concibe el proceso ficcional dentro de la literatura. Si bien en la primera parte del libro se describen las anécdotas de la familia de Gabriel García Márquez, como los hechos del matrimonio de sus padres y las posiciones sociales distintas de ambos, entendemos de qué forma esos acontecimientos perturbadores van constituyendo lo que Vargas Llosa nomina como "demonios" del escritor, es decir, hechos, acontecimientos que no son comunes y que, por su peculiaridad, van quedando registrados en la memoria de García Márquez. La "realidad real” la constituyen acontecimientos que no son ordinarios, sino que constituyen "casos literarios" por la forma exagerada o grandiosa como suceden. De esta forma, trascienden la simple anécdota familiar.

Este método de analizar los hechos biográficos no conforma una metodología estéril para la explicación del fenómeno literario, como podría deducirse en principio para el especialista en literatura. Más bien, constituye una forma particular de explicarlo: Un método que parte de la experiencia del escritor. Por eso, se citan la guerra civil colombiana, la fiebre bananera, la matanza de los huelguistas, Aracataca y la familia, etc. Asimismo, se agrega detalles de la biografía del autor de Cien años de soledad extraídos de un exhaustivo trabajo casi periodístico. En la segunda parte, Vargas Llosa alude a los denominados "demonios", que no son otra cosa que las pulsiones personales prefijadas como obsesiones y que conducen al deicidio:

Escribir novelas es un acto de rebelión contra la realidad, contra la creación de Dios que es la realidad. Es una tentativa de corrección, cambio o abolición de la realidad real, de su sustitución por una realidad ficticia que el novelista crea... Cada novela es un deicidio secreto, un asesinato simbólico de la realidad (85).

Esta concepción de la escritura literaria sobre el acto de rebelión contra la realidad es metafórica. No guarda relación con los registros teóricos que enfatizan la escritura literaria desde una perspectiva racional o subjetiva. La segunda parte que está constituida por la realidad ficticia nos ayuda a entender cómo Vargas Llosa comprende el elemento ficcional de la literatura. Intenta explicar los lazos entre esos demonios interiores del escritor que constituyen su experiencia vital 
para la construcción de esa nueva realidad autónoma en la novela. Por esta razón, esta definición de realidad ficticia proyecta una realidad total, y a través de esta se quiere componer una novela total, que no es otra cosa que la mayor ambición de los escritores realistas latinoamericanos.

El modelo de novela europeo del siglo XIX, elaborado por Tolstoi, Dostoievski, Flaubert, Balzac, entre otros, presupone un grado de representación mayúsculo que requiere captar todos los estratos sociales dentro de su novela. No es el orden histórico el que cuenta, sino la forma de mayor representación que presupone una mayor riqueza literaria. Como se afirma en el último punto de esta segunda parte del estudio, la hegemonía de lo imaginario se logra a través de la construcción de un mundo autónomo que el lector puede identificar y sentir casi como real.

Los modelos literarios de García Márquez incluyen a muchos escritores que forman parte, también, a los de Vargas Llosa: Faulkner, Hemingway, Borges, las novelas de caballerías, etc. Y de estos ambos asimilan las técnicas para el funcionamiento de las novelas. Vargas Llosa se detiene en Cien años de soledad (1967) para examinar peculiaridades en los tipos de narrador utilizados, el tiempo circular, los planos de realidad objetiva e imaginaria, entre otros aspectos técnicos que constituyen la base de la composición ficcional literaria.

Como hemos afirmado anteriormente, la relación entre la "realidad real" y la "realidad ficcional" conforma parte de la teoría de la novela de Vargas Llosa. Al parecer, al igual que su compañero de generación, GM, el objetivo es construir una novela total. Para ello, el elemento ficcional debe proyectar la mayor cantidad de grados de representación social. Los denominados demonios literarios constituyen parte de la experiencia vital de los escritores, y gracias a ellos se puede partir para, con estas obsesiones, diseñar el mundo ficcional requerido en su literatura.

Entonces, para Vargas Llosa la literatura podría definirse desde una perspectiva ideológica y estética. A través de ella podemos entender el aparato ficcional motivado por las obsesiones de los escritores y la manera técnica como construyen sus novelas. Al describir los elementos de constitución técnicos para elaborar las ficciones de GM (realidad real, realidad ficcional, realidad total, demonios, tiempo circular, etc.) y al citar a escritores modélicos comunes, Varga Llosa no solo describe la teoría de novela del autor de El coronel no tiene quien le escriba, sino, además, describe su propia teoría de la novela. Es la mirada de un espejo generacional.

\section{La orgía perpetua (Flaubert y Madame Bovary), el concepto de literatura en la dimensión estética}


La orgia perpetua (Flaubert y Madame Bovary) (1975) es un ensayo literario que se divide en tres partes; la primera referida a su impresión personal sobre la novela; la segunda en los hechos histórico- biográficos de Flaubert y la gestación de la novela; y la tercera sobre los aspectos técnicos y comparativos para la construcción de esta. Vargas Llosa propone un ensayo crítico basado en tres métodos: el impresionista, analítico y el histórico-literario. Aunque por momentos, los tres se entrecruzan en alusiones comparativas. Dentro de sus mayores cuestionamientos, figura el de la creación literaria misma. Explica que Flaubert utiliza su experiencia vital como fuente primaria para la elaboración de sus ficciones. El método de trabajo del escritor constituye la segunda parte del ensayo.

Esto significa que el novelista no crea a partir de la nada, sino en función de su experiencia, que el punto de partida de la realidad ficticia es siempre la realidad real tal como la vive el escritor. Ciertos temas se le imponen, igual que el amor y el sufrimiento, los deseos y las pesadillas. Esto no quiere decir, naturalmente, que la "inspiración" baje hacia él como un efluvio celeste, sino, sencillamente, que tiene un pasado y un presente, una suma de experiencias, algunas de las cuales le sirven de materiales de trabajo. (p.36)

Aquí Vargas Llosa retoma un punto importante para su teoría de novela, el que la experiencia vital convierta esos hechos de la vida que se transforman en obsesiones. Al igual que en Historia secreta de una novela y el estudio sobre GM, resalta esta idea en el ensayo sobre Flaubert. Su concepción de novela parte de la biografía para entender el proceso de la elaboración ficcional.

Con Flaubert ocurre una curiosa paradoja: el mismo escritor que convierte en tema de novela el mundo de los hombres mediocres y los espíritus rastreros, advierte que, al igual que en poesía, también en la ficción todo depende esencialmente de la forma, que ésta decide la fealdad y la belleza de los temas, su verdad y su mentira, y proclama que el novelista debe ser, ante todo, un artista, un trabajador incansable e incorruptible del estilo. (1975, p. 95)

Esa obsesión por la estética del estilo le lleva a proponer que la novela es "la forma". El lenguaje es el gran protagonista de Madame Bovary (2005). Vargas Llosa cita anécdotas sobre cómo Flaubert trabajó el perfeccionamiento de la prosa. Se asume aquí su preponderancia, incluso 
por encima del mismo tema o argumento. Este sería otro elemento fundamental para comprender el proceso creativo. La elaboración de un lenguaje que no solo acompañe a la descripción de los hechos y personajes, sino que su composición, a la manera de la poesía, conforma una dimensión estética que armonice un estilo propio.

La prosa narrativa, según esta concepción, debe poseer un trabajo de perfeccionamiento estético solo comparable a la poesía. La dimensión estética no solo reside en el campo ficcional, sino también en cómo se articula el lenguaje en la novela. Este es un elemento clave para comprender una concepción de novela de Flaubert y, por ende, a Vargas Llosa. Aquí se enfatiza el carácter estético de la novela. Y si bien este género no era comparable a este tipo de definiciones o características, de pronto, gracias a Flaubert, lo adquiere. De esta forma, Vargas Llosa toma este ejemplo para agregar esta característica a su teoría de la novela. Un elemento que, por ejemplo, no estaba definido ni explicado en esta dimensión en sus anteriores trabajos. Flaubert constituye el mejor modelo del trabajo elaborado por un escritor en cuanto a la "forma literaria del lenguaje". Luego, enumera elementos sobre la técnica literaria, como el monólogo interior (el estilo indirecto libre), el antihéroe. Todos estos elementos configuran en mayor o menor medida los aspectos técnicos de la novela. En cuanto al debate sobre lo ideológico o social sobre el arte, existe, también, un punto que se aborda se manera relevante:

Pero hay una importante comarca de la literatura contemporánea — concierne más al teatro y a la poesía que a la novela — que está en absoluto desacuerdo con las teorías de Flaubert sobre la impasibilidad y neutralidad del creador, su condena de la literatura probante y la autonomía de la obra de arte respecto de la vida. Me refiero a esa corriente pedagógica y ética según la cual verdad histórica y verdad artística son inseparables y que asigna a la literatura la responsabilidad de educar a los hombres ideológicamente, describiéndoles los problemas que viven, suministrándoles la interpretación correcta de sus causas y efectos y las armas para remediarlos. (p.100)

Es aquí donde Vargas Llosa se divorcia totalmente de esa responsabilidad social e ideológica de la filosofía sartreana. La dimensión estética está por encima de la ideológica. La ideología no puede poseer ni justificar la obra literaria. Más adelante, se describe las actitudes casi apolíticas de Flaubert, y aunque estas son contrarias de la personalidad de Vargas Llosa (pues sigue siendo un escritor político a pesar de seguir la línea de Flaubert), la valoración estética supera la 
concepción de superioridad ideológica. En eso diferenciaba a Brecht de Flaubert. Dos posiciones distintas. En ese sentido, resalta no solo el carácter pesimista sobre la humanidad del segundo, sino, también, su consideración elevada sobre el arte, y que representaba en la literatura un grado de perfeccionamiento extraordinario para el género.

\section{Conclusiones}

A manera de conclusiones podemos sintetizar las siguientes. En primer lugar, Vargas Llosa posee una elaborada perspectiva sobre su concepción de literatura. Esta parte desde la óptica del escritor como creador y no como teórico. Es importante esta precisión dado el carácter relativo para la definición de literatura en la actualidad. En segundo lugar, y luego de las lecturas seleccionadas, podemos inferir que la literatura para Vargas Llosa es un arte, cuyas características son definidas desde una perspectiva ética y social. En ese sentido, su conceptualización es similar a la de otros escritores, como Virginia Woolf, Ezra Pound o Umberto Eco. En un primer momento, valora el plano ideológico (influencia sartreana), para después priorizar el estético. La literatura es ideología, pero, también, es ficción (parte de una experiencia vital, los "demonios" y la autorreferencialidad). La literatura es un arte cuya elaboración está dirigida por las técnicas narrativas, el estilo y la forma del lenguaje. Algunos elementos que constituyen su teoría de la novela lo son, también, para construir el aparato ficcional.

En tercer lugar, el concepto de literatura inferido a partir de los ensayos de Vargas Llosa concibe a la literatura desde una dimensión conservadora. Coincide con Aristóteles y su concepción sobre "el arte de la palabra" en su finalidad estética y la "mímesis" en la representación de la realidad. No obstante, estas coincidencias también agrupan otras características modernas sobre la técnica profesional en la elaboración de ficciones; la valoración de modelos y sus aportes para modernizar las novelas; además de la concepción de la ideología y la política en las obras literarias (aunque por debajo del plano estético). Si bien el marco teórico sobre el concepto de literatura sigue ampliando sus fronteras de acuerdo con las investigaciones interdisciplinarias y a las modas importadas, no se puede dejar de lado el concepto que propone un creador, y que, a su vez, posee una gran repercusión para el público lector. A veces los intentos por ampliar los significados de una categoría o disciplina terminan diseminándola de manera que pierde su especificidad e importancia para la sociedad. 


\section{Referencias}

Carpentier, A. (1949). El reino de este mundo. Editorial Alfred A. Knopf.

Eagleton, T. (1988). Una introducción a la teoría literaria. Fondo de Cultura Económica.

Eco, U. (2000). La literatura: pasión que cambia la realidad. https://www.lanacion.com.ar/cultura/la-literatura-pasion-que-cambia-la-realidad$\operatorname{nid} 215999 /$

Fernández Cozman, C. (2014). Francia y su literatura en la ensayística de Mario Vargas Llosa. Tonos digital, 27. http://www.tonosdigital.com/ojs/index.php/tonos/article/view/1131

Flaubert, G. (2005). Madame Bovary. Cátedra.

García Márquez, G. (1967). Cien años de soledad. Editorial Sudamericana.

James, H. (2001 ). Otra vuelta de tuerca. Siruela.

Joyce, J. (1999). Ulises. Cátedra Madrid.

Kafka, F. (2012 ). La metamorfosis. Octaedro.

Morales Mena, J. (2018). Mario Vargas Llosa: "La literatura es fuego". Una aproximación. Tesis. http://revista.letras.unmsm.edu.pe/index.php/te/article/view/733

Oquendo de Amat, C. (1927). Cinco metros de poemas. Editorial Minerva.

Pound, E. (1934). ABC of Reading. Faber and Faber.

Sartre, J. P. (1967). ¿Qué es la literatura? Losada.

Sterne, L. (2005 ). Vida y opiniones del caballeroTristam Shandy. Cátedra.

Todorov, T. (1991). Los géneros del discurso. Monte Ávila.

Vargas Llosa, M. (1963). La ciudad y los perros. Seix Barral.

Vargas Llosa, M. (1966). La casa verde. Seix Barral.

Vargas Llosa, M. (1969). Conversación en la Catedral. Seix Barral.

Vargas Llosa, M. (1971a). Historia secreta de una novela. Tusquets.

Vargas Llosa, M. (1971b). Gabriel García Márquez: historia de un deicidio. Barral editores.

Vargas Llosa, M. (1975). La orgia perpetua (Flaubert y Madame Bovary). Taurus.

Vargas Llosa, M. (1981a). Flaubert, Sartre y la nueva novela. En M. Vargas Llosa, Entre Sartre y Camus. Ediciones Huracán.

Vargas Llosa, M. (1981b). Los otros contra Sartre . En M. Vargas Llosa, Entre Sartre y Camus. Ediciones Huracán.

Vargas Llosa, M. (1981c). Sartre, veinte años después . En M. Vargas Llosa, Entre Sartre y Camus. Ediciones Huracán. 
Vargas Llosa, M. (1985). La literatura es fuego. En M. Vargas Llosa, Contra viento y marea (págs. 132-137). Seix Barral.

Vargas Llosa, M. (1997). Cartas a un joven novelista. Editorial Planeta.

Wellek, R., \& Warren, A. (1969). Teoría Literaria. Gredos.

Woolf, V. (1929). A Room of One's Own. http://gutenberg.org . 